\title{
S.] ПОЛИТИЧЕСКИЕ
}

Озтюрк А.

\section{ОСВЕЩЕНИЕ ПЕРЕГОВОРОВ РОССИИ И ТУРЦИИ ПО ГАЗОПРОВОДУ «ЮЖНЫЙ ПОТОК» В ТУРЕЦКОЙ ПРЕССЕ}

\begin{abstract}
Аннотация: Предмет исследования: характер освещения переговоров России и Туриии по строительству газопровода «Южный поток» в турецких печатных СМИ. Автор анализирует разные мнения аналитиков по поводу строительства этого трубопровода. Приводятся также мнения представителей разных политических партий по данному вопросу. В статье демонстрируется, что среди аналитиков турецких СМИ и руководителей партий есть как сторонники, так и противники «Южного потока». Автор делает акиент на антагонизме двух трубопроводных проектов - «Южного потока» и «Набукко». Анализ (автор анализирует различные материалы, посвященные выбранной тематике); компаративистика (сравнение), автор сравнивает как отличается характер освещения переговоров по строительству газопровода в зависимости от характера издания и анализируемого переговорного этапа, а также принции историзма - автор анализируется предпосылки существующих исторических условий, а такэе проводит анализирует ход переговоров с учетом существующей исторической ситуации и общего характера российско-туреиких отношений. Научная новизна статьи состоит в следующем: несмотря на растущее влияние СМИ, их роль в обществе до сих пор остается слабо изученным вопросом гуманитарных наук в России. Автор статьи демонстрирует, как эволючионировала позиция туреиких СМИ в отношении строительства газопровода «Южный поток», а также как разные политические силы и отдельные аналитики оценивают этот проект. В статье делается акиент на конкурентной составляющей двух проектов по транспортировке газа в Европу - «Южного потока» и «Набукко», которые отвечают интересам разных групп стран. Туриия в этой ситуации оказалась в центре политического внимания, поскольку от её решения и согласия на строительство «Южного потока» стала зависеть энергетическая безопасность Европь. Противники присоединения Туриии к этому проекту говорят о необходимости покончить с зависимостью Европы от российского газа, путем участия в проекте «Набукко», который в обход России должен был доставлять газ из Центральной Азии в Европу. Сторонники «Южного потока» наоборот считают его выгодным проектом для Туриии в условиях растущего потребления газа и с учетом выгодных условий, которые предоставила их стране Россия при подписании договора о строительстве газопровода.
\end{abstract}

Review: The subject under research is the coverage of negotiations between Russia and Turkey regarding construction of the gas line 'South Stream' in Turkish print media. The author of the article analyzes different opinions of experts on construction of this gas line. The author also provides opinions expressed by the representatives of different political parties on the matter. It is demonstrated that there are those who approve and disapprove of the South Stream among experts of both Turkish print media and political parties. The author focuses on the antagonism of the two gas line projects, the South Stream and Nabucco. In his research the author uses the methods of analysis and comparison. He analyzes how the opinions expressed regarding construction of the gas line depended on the nature of a particular publishing house as well as the period of negotiations being analyzed. The author also uses the principle of historicism to analyze prerequisites for the current historical conditions and study the course of negotiations taking into account the current historical situation and general nature of the Russian-Turkish relations. The novelty of the article is in the following: despite the growing influence of mass media, their social role is still understudied by the Russian humanities. The author of the present article demonstrates the development of the opinion of Turkish mass media on construction of the South Stream gas line and describes what opinion different political parties and individual analysts expressed on the matter. The author emphasizes that the two projects of constructing gas lines to bring gas to Europe, the South Stream and Nabucco, meet interests of different groups and therefore compete with each other. This has put 


\section{Политика и общество $9(117) \cdot 2014$}

Turkey in the center of political attention because the European security of energy supply is now dependent on the decision of Turkey to construct the South Stream. Those who speak against Turkey joining this project say it is necessary for Europe to stop being depended on the Russian gas by participating in the Nabucco project aimed at delivering gas from the Central Asia to Europe by-passing Russia. On the contrary, those who approve of the South stream, believe it to be an advantageous project for Turkey taking into account the growing volumes of consumed gas and favorable terms offered by Russia to Turkey when signing the agreement on construction of the gas line.

Ключевые слова: «Южный поток», «Набукко», Туриия, Россия, газопровод, газ, энергоресурсы, российско-туреикие отночения, СМИ, пресса.

Keywords: South Stream, Nabucco, Turkey, Russia, gas line, gas, energy resources, Russian - Turkish relations, mass media, print media.

$\mathrm{B}$ первые тема переговоров между Россией и Турцией по «Южному потоку» начинает освещаться турецкой прессой в июне 2007 года, когда Россия заключила договор с Италией о поставках газа через новую систему трубопроводов, проложенных по дну Черного моря. О позиции Турции может свидетельствовать само название первой новостной заметки о проекте, опубликованной в газете «Заман»: «Российская газовая атака на Европу» ${ }^{1}$ В заметке выражается справедливое беспокойство по поводу того, что Россия хочет избавиться от посредничества транзитеров и установить полную монополию на транспортировку газа из Центральной Азии.

По мере развития проекта беспокойство турецких аналитиков увеличивалось. «Южный поток» с самого начала стали воспринимать как альтернативу известному проекту «Набукко», с помощью которого планируется обеспечить транзит газа из Центральной Азии через Каспийское море и территорию Турции. Турецкая пресса в 2007 году признавала «Набукко» главным проектом для Турции и писала о том, что возникновение альтернативных вариантов является крайне нежелательным для их страны². Однако в той же газете в 2008 году турецкий эксперт Сохбет Карпуз констатирует очевидное: без Ирана, и пока статус Каспийского моря остается неопределенным, решить проблему «На-

\footnotetext{
${ }^{1}$ Rusya'dan Avrupa'ya doğalgaz atağı // Zaman (URL: http:// www.zaman.com.tr/haber.do? haberno $=555462 \&$ keyfield $=$ 47C3ВС6Е657920416BC4B16D (дата обращения на сайт 15.08.2014)).

2 Türkiye merkezli Nabucco projesine karşıtlığıyla bilinen Rusya, Avusturya'ya Güney Akım Doğalgaz Boru Hattı projesine katılması için davette bulundu // Zaman (URL: http://www. zaman.com.tr $/$ haber.do?haberno $=577167 \&$ keyfield $=47 \mathrm{C} 3 \mathrm{BC} 6 \mathrm{E}$ 657920416BC4B16D204E61627563636F (дата обращения на сайт 15.08.2014)).
}

букко» нельзя, а значит, Россия остается монополистом в экспорте туркменского и узбекского газа, цена на который устанавливается единолично Россией. Зависимые от поставок газа европейские государства (Италия, Австрия) вынуждены идти на соглашение с Газпромом на невыгодных для себя условиях именно из-за отсутствия реальных альтернатив и желания иметь постоянный источник газа ${ }^{3}$.

Ряд экспертов высказывались за политическую версию конфликта. Эрдал Саглам считает, что желание России провести газопровод по дну Черного моря в обход Турции вызвано геополитическим противостоянием с США. С точки зрения автора, вся ситуация с транспортировкой газа является следствием длительного военно-политического конфликта, главными составляющими которого являются переговоры о размещении ПРО в Европе, расширение НАТО и сокращение ядерных зарядов ${ }^{4}$. Автор предостерегает Турцию от вмешательства в этот конфликт и выражает надежду на то, что заявленное в 2009 году «стратегическое сотрудничество» между Россией и Турцией не изменит стремления турецкого правительства по интеграции в Западные структуры.

Фактически с 2008 года стало понятно, что Россия стремится провести газовые потоки в обход Турции, однако, для этого было необходимо взять разрешение у Анкары на использование шельфа. Формально отказать Турция не могла, да и недальновидно сеять недоверие между успешными пар-

\footnotetext{
${ }^{3}$ Karbuz S. Güney Akım ve Nabucco'nun Türkmen gazıyla tangosu // Zaman (URL: http://www.zaman.com.tr/haber.do?hab erno $=674376 \&$ keyfield $=47 \mathrm{C3BC6E657920416BC4B16D} \mathrm{(дата}$ обращения на сайт 15.08.2014)).

4 Sağlam E. ABD-Rusya ilişkileri ve Türkiye'nin enerji oyunu // Zaman (URL: http://hurarsiv.hurriyet.com.tr/goster/ShowNew. aspx?id=12018306 (дата обращения на сайт 15.08.2014)).
} 
тнерами. Однако следовало самым серьезным образом продумать требования, которые необходимо предъявить России в обмен на предоставление права проложить новый газопровод. Именно эта тема и становится основным предметом обсуждения на переговорах по газовым контрактам между Россией и Турцией, а также в турецкой прессе.

Следует отметить, что проблема конкуренции между двумя газопроводными схемами значительно увеличила роль Турции в регионе. Дело в том, что от её позиции по «Южному потоку» и от её согласия или несогласия реализовать этот проект стала зависеть энергетическая безопасность в Европе. Министр энергетики и природных ресурсов Турции Танер Йылдыз на церемонии открытия газовой электростанции в пригороде Антальи заявил, что споры вокруг реализации проектов «Набукко» и «Южный поток» превратили Турцию в ведущего игрока региона и значительно усилили ее геополитическую роль. По словам министра, «Турция готова сотрудничать и с «Набукко», и с «Южным потоком» ${ }^{5}$.

Слова турецкого министра оправдались в том же году. И Россия, и Европа предлагали Турции различные привилегии, если она даст зеленый свет их вариантам развития газотранспортной системы. Сторонники реализации проекта «Набукко» в Европе обещали ускорить процесс вступления Турции в $\mathrm{EC}$, если она активизирует свое участие. Российская же сторона обещала доход не менее 1 млрд. долларов в год в случае согласия на строительство «Южного потока» ${ }^{6}$. Кстати, впервые в турецкой прессе информация о том, что Турция дает России свое разрешение на строительство «Южного потока» появляется 5 августа 2009 года со ссылкой лично на премьер-министра России В.В. Путина7

Тем не менее, противники присоединения Турции к проекту «Южный поток» представляют свои нео-

\footnotetext{
${ }_{5}^{5}$ Ali Metin Kazancı Doğalgaz santrali açıldı // Zaman (URL: http://www.zaman.com.tr/haber.do ?haberno=882448\&keyfiel $\mathrm{d}=47 \mathrm{C} 3 \mathrm{BC} 6 \mathrm{E} 657920416 \mathrm{BC} 4 \mathrm{~B} 16 \mathrm{D}$ (дата обращения на сайт 15.08.2014)).

${ }^{6}$ Türkiye, gazdan yılda 1 milyar dolar kazanacak // Zaman (URL: http://www.zaman.com.tr/ haber.do?haberno=879257\&keyfiel $\mathrm{d}=47 \mathrm{C3BC6E657920416BC4B16D} \mathrm{(дата} \mathrm{обращения} \mathrm{на} \mathrm{сайт}$ 15.08.2014)).

${ }^{7}$ Rusya: “Türkiye Güney Akım'a izin veriyor" // Zaman, (URL: http://www.zaman.com.tr/ haber.do?haberno=877337\&keyfiel $\mathrm{d}=47 \mathrm{C3BC6E657920416BC4B16D} \mathrm{(дата} \mathrm{обращения} \mathrm{на} \mathrm{сайт}$ 16.08.2014)).
}

споримые аргументы. Колумнист газеты «Хюрриет» Дженгиз Чандар пишет, что необходимо покончить с зависимостью от российского газа через активное участие в «Набукко». С точки зрения автора, этот проект в случае его реализации принесет Турции огромные дивиденды как экономического, так и политического характера. Преодоление монополии России на поставку газа в Европу делает Турцию геополитическим перекрестком между ЕС и постсоветским пространством, которому трудно порвать с наследием СССР. Реализация «Набукко» сделает также неизбежным стратегический выбор Турции в пользу интеграции в Европу. Турция наконец станет полноправным «европейцем» и «похоронит Севрский синдром» ${ }^{8}$. Автор подробно описывает огромные запасы газа Туркменистана, Казахстана, Азербайджана и Узбекистана, которые могли бы заполнить трубопровод и стать надежным источником топлива для Европы. Россия, с точки зрения Дж. Чандара, таким источником не является, так как не смогла договориться с Украиной о транзите, в результате чего люди на Балканах остались без отопления, а работа заводов была приостановлена.

Дж. Чандар вступает в полемику с теми авторами, которые скептически относятся к потенциальному участию Турции в «Набукко», мотивируя это угрозой религиозного фундаментализма и терроризма в странах Центральной Азии. С их точки зрения, эти факторы могут негативно сказаться на стабильности поставок углеводородов. И здесь Дж. Чандар цитирует политолога Мустафу Айдына: «Самая большая угроза для Турции - это остаться за пределами Европейского Союза. Если Турция не часть Европы, не часть Запада, то она обречена постоянно колебаться, подобно стрелке компаса» 9.

Схожую позицию занимает и депутат от партии Националистического Движения Октай Вурал. Он прямо заявляет, что проект «Южный поток» противоречит интересам Турции. Особенно это касается подписания Россией договора по передаче 15\% проекта Франции. Он считает, что Турции следует разрабатывать собственные проекты добычи и транспортировки газа, тем более что значительные его

\footnotetext{
8 Çandar C. Nabucco imzası "Sevr Sendromu"nun defin belgesidir // Hürriyet (URL: http://hurarsiv.hurriyet.com.tr/ goster/ShowNew.aspx?id=12064944 (дата обращения на сайт 16.08.2014)).

9 Ibid.
} 


\section{Политика и общество 9 (117) • 2014}

запасы есть в непосредственной близости от её границ: в арабских странах и на шельфе вблизи Кипра. С точки зрения депутата, Турция уже реализовала проект, позволяющий избавиться от зависимости от российских энергоресурсов - «Баку - Тбилиси Джейхан», и ей следует дальше действовать в именно этом направлении ${ }^{10}$.

Того же мнения придерживаются Туран Йылмаз и Мерве Эрдиль в своей статье «В Анкаре будет подписано соглашение на 7,9 млрд. евро», посвященной заключению договора о строительстве «Набукко». С точки зрения комментаторов, следует все силы бросить на реализацию проекта, и тогда первый газ будет доставлен в Турцию в 2014 году. Россию и США, по их мнению, следует тоже пригласить к участию, таким образом, будут соблюдены все необходимые формальности и российско-турецкие отношения не пострадают ${ }^{11}$.

Интересный выход из создавшегося положения предлагает колумнист «Заман» Фикрет Эртан. С его точки зрения, очевидно, что «Набукко» и «Южный поток» - два конкурирующий проекта, и их одновременная реализация может привести к ухудшению взаимоотношений между их участниками. Также очевидно, что «Набукко» невозможно построить в самом ближайшем будущем, поскольку существует проблема взаимоотношений европейских участников проекта с Ираном. В этих условиях, автор предлагает полностью отказаться от реализации существующих проектов и создать новый, который бы отвечал требованиям всех участников. В качестве одной из альтернатив предлагается «Белый поток» - проект, участие в котором могли бы принять и Россия, и Грузия, и Украина, и Турция. Совместная работа над взаимовыгодной транспортировкой газа, с точки зрения Ф. Эртана, позволит улучшить и политические взаимоотношения между странами ${ }^{12}$. Однако эти предложения не были рассмотре-

${ }^{10}$ Vural: Güney Akım Projesi Türkiye'nin menfaatlerine değil // Posta (URL: http://www.posta.com.tr/ekonomi/HaberDetay/ Vural_Guney_Akim_Projesi_Turkiye_nin_menfaatlerine_ degil.htm?ArticleID $=1 \overline{11865}$ (дата обращения на сайт 16.08.2014)).

${ }^{11}$ Yllmaz T. Erdil M. 7.9 milyar Euro'luk Nabucco imzas1 Ankara'da atılacak // Hürriyt (URL: http://hurarsiv.hurriyet.com. tr/goster/ShowNew.aspx?id=12001841 (дата обращения на сайт 16.08.2014)).

${ }^{12}$ Ertan F. Şimdi de Beyaz Akım // Zaman (URL: http:// www.zaman.com.tr/yazar.do?yazino $=\quad 647958 \&$ keyfield $=4$ ны участниками международных газотранспортных проектов, и дискуссия вновь развернулась вокруг уже существующих проектов.

Как известно, несмотря на большое количество противоречий, соглашение о проведении газопровода «Южный поток» между Россией и Турцией было подписано в Москве 28 декабря 2011 года. До сих пор официально неизвестно, на какие уступки пошла Россия для того, чтобы убедить Турцию дать разрешение на строительство газопровода. В турецкой прессе эксперты по-разному оценивают результаты соглашения.

Газета «Хурриет» обвиняет подписавшего договор министра Танера Йылдыза в том, что он не разглашает подробности соглашения. Комментатор Зейнеп Гюрджанлы спрашивает: «Путин столько времени добивался от Турции подписания этого соглашения, после заключения договора объявил, что вступает в новую эру отношений с Турцией, однако, почему мы не знаем, в какую цену обошлось нашей стране это соглашение?» ${ }^{13}$.

Такое же непонимание на страницах издания «Миллиет» высказывает депутат турецкого парламента от оппозиционной Народно-республиканской партии Недждет Памир: «Мы подписали соглашение о Южном потоке. И какие выгоды получили взамен? На Запад будет идти до 6 млрд. кубометров газа ежегодно, причем потребители газа представляют частный сектор. Получили ли мы скидку на газ, или приняты новые условия по импорту газа, мы не знаем» ${ }^{14}$.

Совсем другого мнения придерживаются журналисты и комментаторы, которые являются сторонниками правящей партии Справедливости и Развития.

Первый намек на некие особые цены на российский газ, получаемый Турцией, сделал министр энергетики Танер Йылдыз 29 декабря 2011 года во

7C3BC6Е657920416BC4B16D (дата обращения на сайт 17.08.2014)).

13 Gürcanlı Z. Gürcistan'dan Osetya'ya büyük operasyon // Zaman (URL: http://www.zaman.com.tr/haber.do?haberno= 723666\&title=gurcistandan-osetyaya-buyuk-operasyon (дата обращения на сайт 17.08.2014)).

${ }^{14}$ Rusya'ya 'yılbaşı hediyesi' Güney Akım Boru Hattı izni // Milliyet (URL: http://www.ekonomi.milliyet.com.tr/rusyaya-yilbasi-hediyesi-guney-akim-boru-hatti-izni/ekonomi/ ekonomidetay/29.12.2011/1481725/default.htm (дата обращения на сайт 17.08.2014)). 
время пресс-конференции. Он обратил внимание на то, что потребление газа в Турции в последние годы резко увеличилось и составляет 175 млн. м $^{3}$ в сутки $^{15}$. Отсюда проблема импорта газа становится одной из самых значимых для Турции. Однако министерство не собирается отказываться от планов приватизации отрасли, что вкупе со скидками, полученными от России, в итоге приведет к снижению розничных цен для прямого потребителя ${ }^{16}$.

Подробнее об условиях импорта газа из России в результате подписания соглашения о проведении газопровода «Южный поток» написано в статье «Рекорд потребления природного газа», опубликованной в газете «Заман». Со ссылкой на министра энергетики Т. Йылдыза, авторы пишут о 5,6 млрд. $\mathrm{M}^{3}$ природного газа, которые Турция получит со скидкой ${ }^{17}$. Причем, в контракте будут участвовать не только государственная компания Боташ, но и частные компании.

Еще один момент, который обсуждался в рамках переговоров между Россией и Турцией, посвященных «Южному потоку», также стал предметом для обсуждения в прессе. Это вопрос строительства атомной электростанции в Аккую, который тесно привязан к газовым соглашениям. Турецкая «Заман» сообщает, что согласно новому договору к российским поставкам газа более не применяется принцип «бери или плати», а также турецкому потребителю предоставляется значительная скидка. Прямо о привязке строительства АЭС к заключению соглашения по «Южному потоку» не говорится, однако, как представляется автору статьи, связь между этими проектами существует. Фактически создана целая сеть проектов энергетического долгосрочного сотрудничества между Россией и Турцией, среди которых значатся и газопроводы, и хранилища, и АЭС, которая способна стать надежным источником электроэнергии на ближайшие 80-100 лет ${ }^{18}$.

\footnotetext{
15 Bakan Yıldız: Türkiye'de en fazla doğalgaz dün tüketildi // Zaman (URL: http://www.zaman.com.tr/haber.do?haberno=1221480 (дата обращения на сайт 17.08.2014)).

${ }^{16}$ Doğalgazda rekor tüketim // Zaman (URL: http://www.zaman. com.tr/haber.do?haberno= 1221580 (дата обращения на сайт 17.08.2014)).

${ }^{17}$ Ibid.

18 Türkiye, Rusya'dan ek doğalgaz alıyor; gaz sıkıntısı yok // Zaman (URL: http://www.zaman.com.tr/haber.do?haberno=122 1199\&keyfield=47C3BC6E657920416BC4B16D2073616E747 2616C (дата обращения на сайт 17.08.2014)).
}

В статье «Аккую станет примером для всего мира» опубликованной в газете «Йени шафак» еще 16 марта 2011 года отмечается, что премьер-министр Турции Р. Т. Эрдоган связал строительство АЭС и «Южный поток» в одно целое, как единый стратегический энергетический проект, который должен вывести партнерство между Россией и Турцией на новый уровень. «Хотя переговоры еще продолжаются, однако, они должны быть успешно завершены», заявил Эрдоган ${ }^{19}$.

В своей статье, посвященной подписанию соглашения по «Южному потоку» турецкий аналитик Фикрет Эртан подводит следующий итог: «Новейшие достижения в транспортировке газа из России по газопроводам «Голубой поток» и «Южный поток» удовлетворяют потребности Турции в газе. Россия также принимает активное участие в сооружении газохранилищ на территории Турции. Проект «Набукко» же так и остался лишь перспективным проектом. Кризис в Европе также не может способствовать новым инвестициям в «Набукко». Турция избрала самый надежный путь поставок энергии и только выиграла от подписания соглашений по «Южному потоку» с Россией» ${ }^{20}$.

Таким образом, можно прийти к следующим выводам. Очевидно, что газопроводы «Южный поток» и «Набукко» являются конкурирующими проектами, которые отвечают интересам разных групп стран. Турция в этой ситуации оказалась в центре политического внимания, поскольку от её решения и согласия на строительство «Южного потока» стала зависеть энергетическая безопасность Европы. Противники присоединения Турции к этому проекту говорят о необходимости покончить с зависимостью Европы от российского газа, путем участия в проекте «Набукко», который в обход России должен был доставлять газ из Центральной Азии в Европу. Сторонники «Южного потока» наоборот считают его выгодным проектом для Турции в условиях растущего потребления газа и с учетом выгодных условий, которые предоставила их стране Россия при подписании договора о строительстве газопровода.

\footnotetext{
${ }^{19}$ Erdoğan: Akkuyudünyayaörnekolacak//YeniŞafak(URL:http:// yenisafak.com.tr/Dunya/ Default.aspx?t=16.03.2011\&i=308649 (дата обращения на сайт 17.08.2014)).

${ }^{20}$ Ertan F. Güney Akım ve Türkiye // Zaman (URL: http://www. zaman.com.tr/yazar.do? yazino=1222909 (дата обращения на сайт 17.08.2014)).
} 


\section{Политика и общество 9 (117) • 2014}

\section{Библиография:}

1. Rusya'dan Avrupa'ya doğalgaz atağ $/ /$ Zaman (URL: http://www.zaman.com.tr/haber.do? haberno=555462\&keyfield=47 C3BC6E657920416BC4B16D (дата обращения на сайт 15.08.2014)).

2. Türkiye merkezli Nabucco projesine karşıtlığıyla bilinen Rusya, Avusturya’ya Güney Akım Doğalgaz Boru Hattı projesine katılması için davette bulundu // Zaman (URL: http://www.zaman.com.tr/haber.do?haberno=577167\&keyfield=47C3BC6 E657920416BC4B16D204E61627563636F (дата обращения на сайт 15.08.2014)).

3. Karbuz S. Güney Akım ve Nabucco'nun Türkmen gazıyla tangosu // Zaman (URL: http://www.zaman.com.tr/haber.do?ha berno=674376\&keyfield=47C3BC6E657920416BC4B16D (дата обращения на сайт 15.08.2014)).

4. Sağlam E. ABD-Rusya ilişkileri ve Türkiye'nin enerji oyunu // Zaman (URL: http://hurarsiv.hurriyet.com.tr/goster/ ShowNew.aspx?id=12018306 (дата обращения на сайт 15.08.2014)).

5. Ali Metin Kazancı Doğalgaz santrali açıldı // Zaman (URL: http://www.zaman.com.tr/haber.do? haberno=882448\&keyfie ld=47C3BC6E657920416BC4B16D (дата обращения на сайт 15.08.2014)).

6. Türkiye, gazdan yılda 1 milyar dolar kazanacak // Zaman (URL: http://www.zaman.com.tr/ haber.do?haberno=879257\&k eyfield=47C3BC6E657920416BC4B16D (дата обращения на сайт 15.08.2014)).

7. Rusya: «Türkiye Güney Akım'a izin veriyor» // Zaman, (URL: http://www.zaman.com.tr/ haber.do?haberno=877337\&ke yfield=47C3BC6E657920416BC4B16D (дата обращения на сайт 16.08.2014)).

8. Çandar C. Nabucco imzası "Sevr Sendromu”nun defin belgesidir // Hürriyet (URL: http://hurarsiv.hurriyet.com.tr/goster/ ShowNew.aspx?id=12064944 (дата обращения на сайт 16.08.2014)).

9. Vural: Güney Akım Projesi Türkiye'nin menfaatlerine değil // Posta (URL: http://www.posta.com.tr/ekonomi/HaberDetay/ Vural_Guney_Akim_Projesi_Turkiye_nin_menfaatlerine_degil.htm?ArticleID=111865 (дата обращения на сайт 16.08.2014)).

10. Yılmaz T. Erdil M. 7.9 milyar Euro'luk Nabucco imzası Ankara'da atılacak // Hürriyt (URL: http://hurarsiv.hurriyet.com. tr/goster/ShowNew.aspx?id=12001841 (дата обращения на сайт 16.08.2014)).

11. Ertan F. Şimdi de Beyaz Akım // Zaman (URL: http:/www.zaman.com.tr/yazar.do?yazino=647958\&keyfield=47C3BC6 E657920416BC4B16D (дата обращения на сайт 17.08.2014)).

12. Gürcanlı Z. Gürcistan'dan Osetya'ya büyük operasyon // Zaman (URL: http://www.zaman.com.tr/haber.do?haberno=7236 $66 \&$ title=gurcistandan-osetyaya-buyuk-operasyon (дата обращения на сайт 17.08.2014)).

13. Rusya'ya 'yılbaşı hediyesi' Güney Akım Boru Hattı izni // Milliyet (URL: http://www.ekonomi.milliyet.com.tr/rusya-yayilbasi-hediyesi-guney-akim-boru-hatti-izni/ekonomi/ekonomidetay/29.12.2011/1481725/default.htm (дата обращения на сайт 17.08.2014)).

14. Bakan Yıldız: Türkiye'de en fazla doğalgaz dün tüketildi // Zaman (URL: http://www.zaman.com.tr/haber. do?haberno=1221480 (дата обращения на сайт 17.08.2014)).

15. Doğalgazda rekor tüketim // Zaman (URL: http://www.zaman.com.tr/haber.do?haberno= 1221580 (дата обращения на сайт 17.08.2014)).

16. Türkiye, Rusya'dan ek doğalgaz alıyor; gaz sıkıntıs1 yok // Zaman (URL: http://www.zaman.com.tr/haber.do?haberno=122 1199\&keyfield=47C3BC6E657920416BC4B16D2073616E7472616C (дата обращения на сайт 17.08.2014)).

17. Erdoğan: Akkuyu dünyaya örnek olacak // Yeni Şafak (URL: http://yenisafak.com.tr/Dunya/ Default.

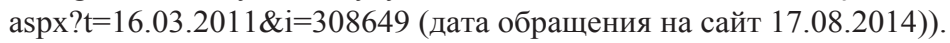

18. Ertan F. Güney Akım ve Türkiye // Zaman (URL: http://www.zaman.com.tr/yazar.do? уаzino=1222909 (дата обращения на сайт 17.08.2014)).

\section{References (transliterated):}

1. Karbuz S. Güney Akım ve Nabucco'nun Türkmen gazıyla tangosu // Zaman (URL: http://www.zaman.com.tr/haber.do?ha berno=674376\&keyfield=47C3BC6E657920416BC4B16D (data obrashcheniya na sait 15.08.2014)).

2. Sağlam E. ABD-Rusya ilişkileri ve Türkiye'nin enerji oyunu // Zaman (URL: http://hurarsiv.hurriyet.com.tr/goster/ ShowNew.aspx?id=12018306 (data obrashcheniya na sait 15.08.2014)).

3. Ali Metin Kazancı Doğalgaz santrali açıldı // Zaman (URL: http://www.zaman.com.tr/haber.do? haberno=882448\&keyfie ld=47C3BC6E657920416BC4B16D (data obrashcheniya na sait 15.08.2014)).

4. Çandar C. Nabucco imzası "Sevr Sendromu"nun defin belgesidir // Hürriyet (URL: http://hurarsiv.hurriyet.com.tr/goster/ ShowNew.aspx?id=12064944 (data obrashcheniya na sait 16.08.2014)).

5. Yilmaz T. Erdil M. 7.9 milyar Euro'luk Nabucco imzası Ankara'da atılacak // Hürriyt (URL: http://hurarsiv.hurriyet.com. tr/goster/ShowNew.aspx?id=12001841 (data obrashcheniya na sait 16.08.2014)).

6. Ertan F. Şimdi de Beyaz Akım // Zaman (URL: http://www.zaman.com.tr/yazar.do?yazino=647958\&keyfield=47C3BC6 E657920416BC4B16D (data obrashcheniya na sait 17.08.2014)). 
7. Gürcanlı Z. Gürcistan'dan Osetya'ya büyük operasyon // Zaman (URL: http://www.zaman.com.tr/haber.do?haberno=7236 $66 \&$ title=gurcistandan-osetyaya-buyuk-operasyon (data obrashcheniya na sait 17.08.2014)).

8. Bakan Y1ldız: Türkiye'de en fazla doğalgaz dün tüketildi // Zaman (URL: http://www.zaman.com.tr/haber. do?haberno=1221480 (data obrashcheniya na sait 17.08.2014)).

9. Ertan F. Güney Akım ve Türkiye // Zaman (URL: http://www.zaman.com.tr/yazar.do? yazino=1222909 (data obrashcheniya na sait 17.08.2014)). 